\title{
A EFETIVIDADE DA LEI DE COTAS DE GÊNERO E O ALARGAMENTO DA PARTICIPAÇÃO FEMININA NA POLÍTICA COM VISTAS AS ELEIÇÕES DE 2018
}

\author{
Julia Monfardini Menuci ${ }^{1}$ \\ Joice Graciele Nielsson ${ }^{2}$
}

RESUMO: Esta pesquisa investiga a crescente participação feminina na política analisando as eleições de 2018 e o aumento do número de mulheres para os cargos de Senadoras, Deputadas Federais e Estaduais. A pesquisa recria o cenário de inferioridade e subjugação a qual a mulher estava inserida anterior ao movimento feminista e o rompimento da dicotomia pública/privada com a conquista de direitos. A problemática de investigação questiona se a Lei de Cotas auxilia na entrada da mulher na política e se há representação através das mulheres eleitas. Conclui-se que a Lei de Cotas vem auxiliando a entrada da mulher na política, contudo, ainda há uma parca participação e uma frágil representação.

Palavras-chave: Eleição. Feminismo. Gênero. Mulheres Eleitas. Participação Política.

\section{THE GENDER QUOTAS LAW EFFECTIVENESS AND THE ENLARGEMENT OF WOMAN POLITICS PARTICIPATION WITH A VIEW OF THE 2018 ELECTIONS}

\begin{abstract}
This research examines the growing female participation in politics analyzing the 2018 elections and the increasing number of women in the positions of Senators, Federal Deputies and State. The research recreates the scenario of inferiority and subjugation to which women were inserted prior to the feminist movement and the end of public/prived dichotomy with the rights conquest. The investigation problematics asks about the Quota Law helps women to enter in the politics and if there is a representation through the elected. The conclusion is that the Quota Law has been helping women to enter politics, however, there's still a small participation of women in this area. Wich entails a small representation of the women themselves from the social environment.
\end{abstract}

KEY WORDS: Feminism. Gender. Elected Women. Political Participation.

\section{INTRODUÇÃO}

$\mathrm{O}$ aparato instrumental jurídico que rege a sociedade utiliza-se de preceitos, costumes, juízos de valor e, principalmente, práticas culturais para ratificar e consolidar a hierarquia do masculino sob o feminino. Nesse diapasão, a desigualdade de gênero, encontrada desde os

1 Doutoranda e Mestre em Direito pela Universidade Regional do Noroeste do Estado do Rio Grande do Sul (UNIJUÍ). Bolsista PROSUC/CAPES. Especialista em Direito Processual Cível (FAVENI).

2 Doutora em Direito Público pela Universidade do Vale do Rio dos Sinos (UNISINOS). Mestra em Direitos Humanos pela Universidade Regional do Noroeste do Estado do Rio Grande do Sul (UNIJUÍ). Professora do curso de Direito da UNIJUÍ e professora do Curso de Pós-graduação em Direito - Mestrado e Doutorado (UNIJUÍ). 
tempos mais remotos, é trazida até a contemporaneidade na forma de normatividade. Os períodos evolutivos da humanidade demonstram que as distinções de gênero resultaram em uma bagagem histórica incrustrada de disparidades pautadas na cultura patriarcal, que primava pela subjugação e inferiorização feminina como regra societária intentando a manutenção de poder e da supremacia masculina.

O estudo em seguimento pretende fomentar a discussão sobre como a desigualdade de gênero interfere no alcance de cargos políticos para mulheres diante de sua consolidação histórica, consubstanciando a teoria patriarcal e a exclusão da mulher do espaço público. As práticas históricas e os eventos que consolidaram a inferioridade de certos grupos - mulheres, negros, etc. - permitiram que fosse criada uma ideia cultural de subalternidade, onde esses indivíduos deveriam internalizar tal característica e agir respeitando sua submissão.

A sociedade foi condicionada a classificar homens e mulheres de acordo com sua constituição biológica, categorizando a mulher como naturalmente inferior a partir da composição do corpo feminino. A capacidade de reprodução, os seios, o útero, o tamanho do cérebro, foram entendidos como aspectos naturalmente femininos, integrantes de sua conjuntura estrutural e biológica. Esses elementos classificam tanto homens como mulheres, através de funções reprodutoras pré-estabelecidas ${ }^{3}$ que foram utilizadas para delimitar a participação feminina no espaço público, resultando em sujeitos submissos e sem direitos, dominados pelo patriarcado (BEAUVOIR, 1980).

Para fomentar o estudo que se apresenta aqui, é importante conhecer a visão de Pierre Bourdieu (1995) quando afirma que a visão da mulher sobre si mesma é uma visão distorcida e colonizada, sob esse aspecto, suas histórias e trajetórias foram contadas sob uma perspectiva patriarcal e sexista. Para isso, foram utilizados discursos de inferioridade baseados em teorias de classificação feminina em detrimento de diferenças biológicas e naturais do sexo, o que acabou por refletir nas leis e constituições criadas, ratificando a mulher em subjugação perante a figura masculina de maneira positivada. A partir da repetição de incansáveis discursos de poder, fez-se com que as sociedades que estão evoluindo aceitem que a posição da mulher no corpo social é de menor valor do que a do homem, e permitiu que fossem construídas leis sobre essa falsa verdade.

3 As funções reprodutoras pré-estabelecidas afirmam que uma mulher, nasce mulher, com suas aptidões voltadas ao privado, aos cuidados com sua prole, e ao desejo matrimonial. Ela deve cumprir esse papel, sendo submissa, boa esposa, e mãe recatada. Quanto ao homem, ele deverá ser o provedor do lar, proteger a família, ser forte, sábio e másculo, para exercer todo seu poder no âmbito público e perpetuar essa hierarquia. 
Em virtude desse panorama, durante o século XIX começam as transformações de pensamento quanto as possibilidades e o próprio papel da mulher no espaço público. Nesse sentido, o movimento feminista surge através da união feminina e de forma organizada ao final do século XVIII e durante o século XIX, adquirindo caráter de movimento político. As demandas feministas se remodelam, o movimento passa a contar com intelectualidade e com um aporte teórico de relevância que auxiliou a luta feminina por direitos negados a elas e por um espaço social menos sexista (COLLING, 2000).

Compreendida como um sistema simbólico de poder, a diferença de gênero é, segundo Scott (2005), a origem mais antiga, universal e poderosa de muitas conceitualizações moralmente valoradas acerca de tudo que nos rodeia. Sua introdução como categoria de análise permitiu perceber que a remodelação do patriarcado (re)produziu estereótipos de gênero, contribuindo para a construção e manutenção da opressão contra mulheres. Todos estes fenômenos, constituídos no contexto de densas relações de poder, são imersos na sociedade contraditória, no qual a ideologia do poder mantém o seu controle sobre a consciência popular.

A dicotomia pública-privada foi/é imprescindível para as teorias e práticas políticas da contemporaneidade assentadas sob a dominação da mulher e sua reclusão à esfera privada, enquanto o homem dominava e circulava em ambas as esferas. Um dos elementos centrais para perpetuar esta situação é a chamada divisão sexual do trabalho, pela qual os homens são vistos, sobretudo, ligados às ocupações da esfera da vida econômica e política e responsáveis por elas, enquanto as mulheres seriam responsáveis pelas ocupações da esfera privada, da domesticidade, do cuidado e da reprodução (ALVES, PITANGUY, 2003).

No momento em que se toma como regra que a mulher deve ocupar o espaço doméstico, deixando o homem seguir seu caminho natural no âmbito público, está se perpetuando práticas históricas. A subjugação do ser feminino, bem como sua exclusão dos espaços de poder, resultou em uma completa falta de atuação fora do espaço privado, tardando a emancipação feminina. Diante desses elementos que nortearão a pesquisa, o objetivo central desse estudo é averiguar a conquista de direitos políticos femininos partindo para a investigação com vistas a responder o problema de pesquisa: a Lei $n^{\circ}$ 9.504/1997 - Lei de Cotas de Gênero - vem possibilitando a atuação da mulher na política ou as práticas patriarcais ainda cerceiam a atuação feminina? 
Para que seja possível responder tal problemática a pesquisa se caracteriza por ser um estudo quantitativo, imbricando em uma pesquisa que se pauta no método indutivo apontando um cenário geral de exclusão e subjugação feminina até a conquista de direitos. Como método de procedimento será empregado o bibliográfico e estatístico tendo em vista que foram captados dados para responder ao problema de pesquisa em comento (LAKATOS; MASCONI, 2003). Por fim, essa pesquisa se estrutura em três capítulos, os dois primeiros irão embasar a construção teórica para que em um terceiro momento se avaliem os números de mulheres eleitas nas eleições de 2018 e quais as implicações diante desse panorama.

\section{A CONQUISTA DE DIREITOS ATRAVÉS DO MOVIMENTO FEMINISTA E SUFRAGISTA}

Introduzido de forma breve alguns aspectos que irão embasar esse artigo, impende mencionar que o movimento feminista - mesmo antes de se denominar assim - sempre buscou uma maior igualdade para as mulheres dentro da sociedade patriarcal. Ele lutou para romper o estereotipo de poder que comandava a ordem social, em prol de que elas adquirissem direitos que já eram auferidos aos homens. Como mencionado acima, a desigualdade de gênero. A participação política foi uma conquista intensa diante da união feminina que fez com que mulheres de muitas partes do mundo se unissem em prol da causa. Sendo um viés do movimento feminista, o surgimento do movimento sufragista assume um caráter reivindicativo em busca de prerrogativas que não eram conferidas às mulheres, os direitos políticos.

O movimento sufragista nasce no plano internacional e vem a refletir diretamente na conquista dos direitos políticos das mulheres brasileiras. Em síntese, o rompimento da dicotomia pública-privada explanada acima se dá junto ao período iluminista, isso porquê através do discurso de igualdade natural entre os indivíduos e, glorificando a razão, bem como o intelecto, o século das luzes (XVIII) trouxe ao cenário europeu uma modificação de pensamento. Os ideários revolucionários que surgiram com o Iluminismo se pautavam na igualdade de Direitos Humanos, mesmo que as mulheres - e muitos outros indivíduos - ainda estivessem segregadas à margem da composição social (MENUCI, 2018). 
Os filósofos iluministas, afirma Nielsson (2016), de um modo geral pregavam a ideia de igualdade, universalidade e liberdade, embora muitos deles excluíssem as mulheres destes valores. Essa exclusão abriu espaço para a reivindicação feminista que teve seu aporte na razão como fundamento de equidade. Sob essa lógica, se a mulher e o homem seriam iguais perante a razão e, eram humanos, então eles deveriam ser igualados na perspectiva social e de direitos. Entretanto, os valores iluministas e burgueses atingiram somente aos homens, perpetuando sua individualidade de direitos de tal modo que assim como foram outros tempos, o Iluminismo também foi um período masculino.

Sob esse panorama, as indesejadas filhas do Iluminismo, Olympe de Gouges e Mary Wollstonecraft $^{4}$, foram exemplos de lutas pelo rompimento das barreiras iluministas que operavam sobre as mulheres, para buscar as faculdades emancipatórias que esse movimento as negou (PULEO, 1999). Para retomar os debates feministas foi preciso a criação de um referencial teórico que surgiu de mulheres tais como as citadas acima, que visavam lutar substancialmente para serem consideradas sujeitos ativos e possuidoras de direitos civis e políticos. As escritas de Olympe de Gouges e Mary Wollstonecraft foram imprescindíveis para atribuir ao movimento feminista uma maior elucidação da existência feminina e intelectualidade na argumentação de demandas.

A libertação do privado diante das produções literárias femininas fez com que as mulheres conquistassem o direito de estudar. Segundo Puleo (1999) esse momento se torna marcante na trajetória feminina visto que é o início de uma caminhada fora do espaço doméstico, originando, inclusive, debates políticos e sociais por parte das mulheres. As principais reivindicações femininas se pautavam em torno de direitos abnegados a elas, tais como: o direito ao trabalho, os direitos matrimoniais e os direitos políticos (PULEO, 1999).

Sob esse panorama, é inegável o impacto que a Revolução teve na vida de toda a Europa, as autoras Branca Alves e Jaqueline Pitanguy (2003) apontam que mesmo com o lema libertário, a Revolução continuou atribuindo a muitos a condição de desigual, isso

\footnotetext{
4 Marie Gouze, que passou a se chamar Olympe de Gouges, nasceu em 1748 e foi uma feminista francesa, dramaturga e ativista, que lutava por igualdade de direitos femininos e questionava a ordem patriarcal em que vivia. Em detrimento de sua atuação política, foi decapitada em 1793. Mary Wollstonecraft, foi uma escritora inglesa, nascida em 1759, também defendia a paridade de gênero. Durante sua carreira escreveu algumas obras de relevância, sendo a mais popular delas Reivindicação pelos Direitos das Mulheres (1792), no qual a autora rebatia as teses naturalistas de inferioridade feminina e afirmava que as mulheres detinham um acesso limitado ao espaço intelectual, o que propiciava somente a evolução racional masculina. Wollstonecraft faleceu dez dias após o nascimento de sua segunda filha por consequências do parto, aos 38 anos.
} 
porque dava poderes somente ao homem branco. Como resultado da Revolução, é publicada a Declaração dos Direitos do Homem e do Cidadão, em 1789, sendo conhecido como o marco do nascimento dos direitos de liberdade e igualdade social. Michele Perrot (2007) afirma que a cidadania abordada na Declaração exclui totalmente a figura feminina, que já vinha de outrora sendo expurgada do vínculo social a que pretendia pertencer.

A Declaração foi o estopim da legitimação da desigualdade, dando o pontapé inicial para o movimento de mulheres que visava a conquista da cidadania. Os Estados Unidos da América (EUA), bem como a Europa, detiveram movimentos sufragistas diferenciados, porém, ambos os movimentos refletem no panorama brasileiro. O sufragismo americano é marcado pela Convenção dos Direitos da Mulher, ocorrida no ano de 1848 na cidade de Seneca Falls, podendo ser considerada um dos aportes iniciais do movimento sufragista nos EUA. Ao longo dos debates na Convenção, é estabelecido que um dos deveres de toda mulher americana era lutar pelo sufrágio, como rememora Branca Alves e Jaqueline Pitanguy (2003). Somente em 1869 o Estado de Wyoming concede às mulheres essa prerrogativa pela primeira vez nos Estados Unidos. Em detrimento disso, muitos outros Estados americanos passam a aderir essa possibilidade, pois detinham soberania para tal (COELHO, 2014).

O movimento sufragista americano durou cerca de 70 anos, em sua fase final ele adquiriu um caráter agressivo e violento assim como na Europa, quando as mulheres já estavam cansadas de lutar por algo que não surtia o resultado esperado, como reporta (BRANCA; MOREIRA, 2003). No que concerne ao sufragismo europeu, ele se diferenciou do americano por portar desde o início a violência como forma de combate à opressão feminina. O esforço das europeias foi similar às americanas, consideradas radicais, elas mobilizavam campanhas, debates e passeatas; como forma de resistência a ordem social e buscando o apoio de parlamentares para modificar a lei (PINTO, 2010).

A luta pela conquista do sufrágio feminino se aloca na primeira onda do movimento feminista, onde as mulheres pioneiras nessas reivindicações ficaram conhecidas como suffragettes (sufragistas). Na Europa, o movimento sufragista tem seu marco em 1903, na cidade de Manchester, quando é fundada a Womens's Social and Political Union. A opressão policial era devastadora, muitas foram as mulheres que sofreram ataques de violência e foram presas em consequência de sua manifestação dentro do movimento (COELHO, 2014). 
Depredando bens e propriedades, as suffragettes estavam buscando direitos que pacificamente não foram atendidos. Colling (2000) relata que antes mesmo do movimento sufragista se formar no Brasil, a primeira Constituição brasileira de 1891 estabelecia em seu artigo 70 que os eleitores das próximas eleições são os cidadãos maiores de 21 anos, esse artigo continha restrições no que tange ao sujeito que poderia votar, porém, nada estabelecia sobre as mulheres, deixando a questão omissa (BESTER, 1997). Diante dessa omissão a atuação feminina só crescia, a exemplo de Myrthes de Campos, a primeira advogada brasileira a ser aceita no Instituto da Ordem dos Advogados, atuando também no Tribunal de Justiça Brasileiro, se alista para pleitear o direito de votar. Seu pedido, obviamente, é indeferido, mas ela não se cala e continua usando de sua posição jurídica para reivindicar direitos femininos ainda abnegados, mobilizando muitas mulheres a aderirem ao movimento (BESTER, 1997).

De acordo com Celi Pinto (2010), a Lei Saraiva foi uma das mais significativas mudanças políticas no Brasil, tendo sua aprovação no ano de 1881, ela instituiu a forma de voto direto, bem como a criação do título eleitoral, sendo resultado da primeira reforma legislativa do Brasil. Gisela Bester (1997, p. 5) destaca que "para ser eleitor o indivíduo deveria cumprir exigências como: ser do sexo masculino, maior de 21 anos e ter uma renda anual". A justificativa para a exclusão das mulheres centrava-se no fato de que elas eram subordinadas aos os comandos do pai ou do marido. O movimento sufragista brasileiro se iniciou em meados de 1910, tendo seu marco quando Leolinda Daltro funda o Partido Republicano Feminino, o primeiro partido composto somente por mulheres. O objetivo central do partido era reavivar a discussão do voto feminino dentro do Congresso Nacional, onde, há muitos anos, havia se estagnado. Leolinda era conhecida como a "Mulher do Diabo", por ser separada e pelos filhos serem criados por parentes para que ela pudesse palestrar pelo Brasil conscientizando mulheres (ARAUJO, 1999).

Ainda, Celi Pinto (2010) destaca que, no ano de 1919, Bertha Lutz fundou a Liga pela Emancipação Intelectual da Mulher, posteriormente denominada de Federação Brasileira pelo Progresso Feminino. Essa organização foi uma das responsáveis na condução do processo pelo sufrágio feminino em território brasileiro. A tática utilizada pela Federação para pressionar o governo patriarcal, segundo Branca Alves e Jaqueline Pitanguy (2003), era a divulgação da atuação feminista na mídia, refletindo na pressão social sobre os membros do Congresso e informando cada vez mais mulheres sobre seus direitos negados. As 
movimentações femininas tomam o país e após muitos anos de luta e manifestações o Estado do Rio Grande do Norte foi o primeiro Estado a conceder a possibilidade de voto a uma mulher (COLEHO, 2014).

Em 1927, Celina Guimarães Viana foi a primeira eleitora registrada no país, a qual requereu seu direito a partir do próprio texto constitucional do Estado que emanava o voto sem fazer distinção de sexos. No ano de 1928, ocorre a primeira eleição em que as mulheres votaram, posteriormente anulada sob justificativa de que era preciso lei específica para tutelar o direito de voto delas. Já em 1929, o Estado do Rio Grande do Norte elegeu a primeira prefeita da América do Sul, na cidade de Lages, Alzira Soriano, exercendo o cargo por um ano (ARAUJO, 1999).

O exemplo que o Estado do Rio Grande do Norte deu ao resto do país foi fundamental para a evolução e conquista do sufrágio nos outros Estados. Esse era mais um passo na missão de comprovar que a mulher tinha capacidade para atuar na política. Com os avanços do século XIX, as mulheres detinham maior discernimento quanto sua posição no mundo e quanto a posição que queriam ocupar na sociedade. $\mathrm{O}$ acesso à educação ajudou muitas delas a evoluírem, abandonando o status de mulheres submissas. Na data de 24 de fevereiro de 1932, o presidente Getúlio Vargas assinou a prerrogativa mais aguardada pelas mulheres, o direito ao voto feminino. No ano subsequente as brasileiras já puderam votar nas eleições, mesmo com o voto sendo facultativo. Apenas em 1946 é que ficou emanado que o voto feminino é um dever (COELHO, 2014).

Celi Pinto (2010) esclarece que, em 1932, foi garantido o direito de voto às mulheres casadas, mediante autorização do marido, bem como às viúvas que auferissem renda própria para seu sustento. Ocorre que esse pré-requisito para o voto impedia as mulheres que ainda não eram casadas, ou que não desejavam o matrimonio, restringindo cada vez mais as possibilidades de libertação feminina. É possível concluir, a partir desse impedimento, que a concessão do sufrágio para as casadas apenas visava a manutenção das regras patriarcais, as quais almejavam a manutenção do status de submissão da mulher perante o marido. Novamente as vontades masculinas estão acima da paridade de gênero, mantendo a mulher sob as rédeas do casamento e do espaço privado, fato esse que será modificado com o advento da Constituição Federal de 1988. 


\section{A LEI DE COTAS E OUTRAS AÇÕES AFIRMATIVAS COM ENFOQUE NA MULHER APÓS A CONSTITUIÇÃO DE 1988}

Como explicitado acima, os direitos políticos e entre eles o voto foram uma conquista árdua. Após a conquista do direito de voto feminino, em 1932, a participação política e a representatividade auferida pelas mulheres no espaço público ainda era escassa. A parca representação feminina na política ainda em 1995 fazia com que as mulheres não tivessem suas demandas abarcadas pelo poder público e quiçá requeressem sobre elas. A participação política feminina ainda era novidade e muitas mulheres mal sabiam como adentrar nesse meio por ser compreendido como um local primordialmente masculino, para modificar esse cenário era preciso de legislação que colocasse as mulheres na política.

Um dos marcos que influenciou diretamente a criação da legislação de cotas não só no Brasil, mas na América Latina, foi a $4^{\text {a }}$ Conferência das Nações Unidas sobre a Mulher, realizada no ano de 1995 em Beijing na China, justamente por esse motivo houve uma grande aderência às cotas por diversos países nos anos posteriores à 1995 uma vez que a ideia foi levada através de governantes às suas nações. Ainda, a Conferência debateu sobre a importância da representação feminina resultando em uma extensiva política de cotas de gênero em diversos países (MARQUES, 2018).

Precursora, a Argentina foi a primeira nação a instituir a política de cotas, no ano de 1991, após, mais quatorze países latino americanos também adotaram, sendo eles México, Costa Rica e Paraguai em 1996, Equador, Panamá, Peru, República Dominicana e Bolívia em 1997, Venezuela em 1998, Colômbia e Honduras no ano de 2000, Uruguai em 2009 e El Salvador em 2013 (MARQUES, 2018). Para o panorama brasileiro é perceptível que também houve nítida influência da Conferência em Beijing, isso porque a Deputada Marta Suplicy que participou do evento volta ao país e propõe o Projeto de Lei de Cotas, em 1995. Esse projeto emanava que os partidos deveriam ter um mínimo de candidaturas femininas, ampliando a participação das mulheres nos espaços de decisão e aumentando sua representatividade. Inicialmente a Lei 9.100/95 previa que nas eleições municipais de 1996 deveria haver 20\% do total de candidaturas reservadas para vereadoras (BRANCA; MOREIRA, 2003).

A Lei de Cotas existente atualmente (Lei 9.504/1997) partiu da Lei 9.100/1995 e de suas diversas modificações, ela reservava $30 \%$ das candidaturas de partidos ou coligações 
para cada sexo em todos os cargos, conforme explana a professora Danusa Marques (2017). O que se vislumbra dos dados acima é que em um primeiro plano a lei de cotas não previa exatamente a inclusão da mulher na política, ela visava a reserva de candidaturas, não o preenchimento efetivo.

Um elemento que consubstanciou a criação da política de cotas foi a modificação do papel da mulher no Estado brasileiro. Em detrimento desse reconhecimento muitas foram as ações políticas que agora se destinavam a elas, a exemplo disso, a promulgação da Constituição Federal de 1988 trouxe os direitos políticos femininos ratificados, bem como proporcionou uma expansão nas ações positivas que englobam a mulher como sujeito emergente de direitos. Seu papel se modificou, e sua inserção na política, bem como o avanço das reivindicações feministas, resultaram na composição de políticas públicas e programas governamentais que reconheciam a necessidade de abordar essas demandas femininas de forma consciente.

A partir deste cenário, no Brasil, muitas das políticas públicas em vigor constituíramse a partir do reconhecimento, por parte do Estado, do processo de exclusão e discriminação historicamente imposto a amplos grupos sociais, entre os quais, as mulheres. Esta intensa organização social em busca de direitos foi denominada, por algumas autoras tal como Heleieth Saffioti (2004), de agenda de gênero. A partir dos anos 1980 essa agenda passou a trazer à tona temas como a violência, visando criar programas abrangentes que atendessem as mulheres vítimas de crimes no âmbito doméstico. Esse eixo pretendia auferir às mulheres atenção integral (jurídica, psicológica e médica), assim como criar abrigos para as vítimas. Através de medidas ligadas à segurança pública, originam-se as delegacias especializadas em crimes cometidos contra mulheres, juntamente com a aplicação de medidas repressivas e preventivas desses crimes que fossem mais efetivas no combate à violência de gênero (BANDEIRA, 2014).

As demandas feministas foram se materializando nas instituições públicas, por meio de ações desenvolvidas de forma transversal e executadas por várias estruturas da própria administração, nas quais se apoiam à perspectiva de reverter as desigualdades ainda persistentes brasileiras. A partir da criação da agenda de gênero, a contribuição dos movimentos sociais e feministas foi decisiva para a consolidação de conquistas em vários setores governamentais. Nesse sentido, a participação política também foi ampliada, uma vez 
que o Estado brasileiro tem promovido a democratização das suas relações com a sociedade por meio da viabilização de espaços de diálogo e de participação, entre eles: fóruns, conferências, consultas públicas; dentre outros mecanismos que possibilitaram que as vozes femininas fossem ouvidas (BANDEIRA, 2014).

No caso das políticas públicas para mulheres, um marco significativo no desencadeamento de um arranjo institucional capaz de desenvover uma estrutura de políticas públicas com tal finalidade foi a criação da Secretaria de Política para Mulheres - SPM, da Presidencia da República, no ano de 2003. Desde sua criação, a SPM passou a desenvolver uma série de Conferências e cartilhas informativas, dissipando conceitos de igualdade de gênero e permeando o espaço nacional com mecanismos de enfrentamento à cultura patriarcal. Ao longo dos primeiro anos, suas ações receberam um número significativo de investimentos para a ampliação dos serviços e criação de outros novos, como Centro de Referência de Atendimento às Mulheres; Defensorias da Mulher; Serviços de Responsabilização e Educação ao Agressor; Promotorias Especializadas; além da construção de Redes de Atendimento às mulheres em situação de violência (MENUCI, 2018).

Muito embora esse órgão tenha se modificado em resultado do novo governo do presidente Jair Bolsonaro, a nova pasta se denomina Ministério da Mulher, da Família e dos Direitos Humanos, a qual supostamente se designa para as mesmas questões que a SPM. Para que haja a criação de espaços de gênero e políticas públicas não-generalistas que foquem o sujeito mulher como objeto central de políticas públicas de gênero é preciso que exista a representação feminina na política do país, para avistar o panorama das mulheres na política no próximo capítulo serão demonstrados quantitativos que refletem essas atuações.

\section{O AUMENTO DO NÚMERO DE MULHERES ELEITAS E CRESCENTE REPRESENTAÇAO FEMININA NA POLÍTICA}

O desenvolvimento da pesquisa se deu a partir da busca de informações públicas disponíveis nos sites do Tribunal Superior Eleitoral onde constam todos os dados acerca das eleições que ocorreram no final do ano de 2018, tal como o número total de candidatos, o número de eleitores, os eleitos e os dados que recaem sobre as mulheres como o número de mulheres eleitas para os cargos de Senadoras, Deputadas Estaduais e Deputadas Federais para 
os mandatos que se iniciavam em janeiro de 2019. O objetivo da análise foi averiguar a efetividade da Lei de Cotas, um dos focos desse trabalho, e posteriormente averiguar se a representatividade feminina no rol político vem crescendo no país.

Inicialmente apresenta-se o número de eleitores no país: conforme os dados do Cadastro Eleitoral haviam 147,5 milhões de eleitores votantes em 2018, sendo que 77 milhões de pessoas nesse universo eram mulheres, ou seja, mais da metade de eleitores recaiam sobre a parcela feminina. $\mathrm{O}$ número de mulheres que se candidataram (e tiveram sua candidatura homologada) para concorrer a cargos políticos nas eleições foi de 9.204 em um universo de 29.126 candidatos, ou seja, 31,6\% dos candidatos eram mulheres. Das 9.204 vagas, 290 mulheres foram eleitas para cargos públicos, resultando em um aumento de $52,6 \%$ se comparado ao ano de 2014 (TSE, 2019).

Em um comparativo dentre as casas, na Câmara dos Deputados, de um total de 513 eleitos, no ano de 2014 foram eleitas 51 mulheres, já no ano de 2018 o número subiu para 77. Quanto ao Senado Federal 7 mulheres foram eleitas senadoras nas últimas eleições, o mesmo número de 2010 visto que em 2014 não foram eleitos 54 senadores como de costume, utilizando-se o ano de 2010 para se ter um comparativo entre o mesmo número de vagas. $\mathrm{Na}$ Assembleia Legislativa, para o cargo de Deputados Estaduais de 1.059 eleitos, em 2014119 foram mulheres e 161 foi o número de mulheres no ano de 2018, também ocorrendo aumento significativo delas (TSE, 2019). Abaixo a tabela demonstra por amostragem os números e as porcentagens correspondentes:

\begin{tabular}{|c|c|c|c|c|}
\hline $\begin{array}{c}\text { Vagas por } \\
\text { cargo }\end{array}$ & $\begin{array}{c}\text { Número de } \\
\text { mulheres } \\
\text { eleitas em } \\
2014\end{array}$ & $\begin{array}{c}\text { Número de } \\
\text { mulheres } \\
\text { eleitas em } \\
2018\end{array}$ & $\begin{array}{c}\text { Porcentagem das } \\
\text { mulheres eleitas em }\end{array}$ & $\begin{array}{c}\text { Porcentagem das } \\
\text { mulheres eleitas em } \\
2014\end{array}$ \\
\hline $\begin{array}{c}\text { Câmara dos } \\
\text { Deputados } \\
513\end{array}$ & 51 & 77 & $9,9 \%$ & $15 \%$ \\
\hline $\begin{array}{c}\text { Senado } \\
\text { Federal 54 }\end{array}$ & - & 7 & & \\
\hline Deputados & 119 & 161 & $11,2 \%$ & \\
\hline
\end{tabular}




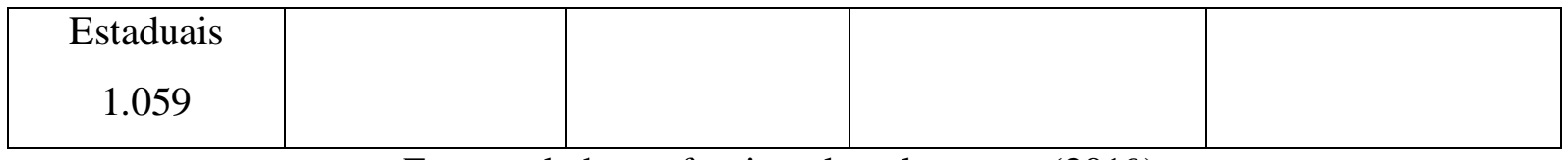

Fonte: tabela confeccionada pela autora (2019).

Diante dos resultados apresentados acima, em um primeiro plano os números de mulheres eleitas parecem exíguos, muito embora se tenha um aumento de mulheres eleitas em todas as casas. Essa participação reduzida pode ser atrelada às razões históricas da exclusão das mulheres da política que diante do confinamento nos espaços privados, apontado no primeiro capítulo dessa pesquisa, as tarefas domésticas ainda recaem sobre as mulheres, fazendo com que a política seja uma segunda atividade nas vidas femininas. A partir da constituição do patriarcado como forma de organização social, se instaura a dicotomia pública/privada, ditando sobre a mulher os locais onde ela pode ou não atuar, acarretando, ainda, em uma consequente subordinação, opressão e discriminação das mulheres dos espaços políticos, o que justifica nos números diminutos (PATEMAN, 1993).

Obviamente a Lei de Cotas de Gênero tem auxiliado no alcance das mulheres em cargos políticos, contudo, desde a redemocratização do país em 1988 a Constituição Federal contém diversos comandos no sentido de incentivar o ingresso das mulheres no espaço da política com vistas a promoção da representatividade de gênero nos espaços de poder. Desde 1988 é possível identificar uma intensa agenda de gênero que nasce com a CF e que intenta posicionar a mulher também no espaço público. O que fica evidenciado é que ainda há um longo caminho a ser percorrido em busca da paridade política. Tal fato apresenta um certo paradoxo, inicialmente se avistam um suposto empoderamento das mulheres, a ponto de viabilizar sua participação política e o aumento dos números de mulheres eleitas, contudo, ao números ainda se mostram baixos se comparados ao número de homens em cargos políticos quando se avista que mais da metade dos eleitores são mulheres.

Isso se deve ao fato de que a estrutura patriarcal se sustenta a partir da perpetuação de estereótipos de gênero, que legitimam e mantém a divisão do poder a partir da lógica sexista, racista e classista. Tais estereótipos de gênero se unem a papéis sociais que diferencia espaços de homens e mulheres, são um dos fatores mais significativos no cerceamento da atuação das mulheres na política. Essas concepções históricas foram trazidas ao campo político moderno e são utilizadas por agentes contrários à participação feminina para lhes retirar o poder anteriormente dado com a Lei de Cotas (VERDADE, 2013). A crença na inferioridade 
feminina foi trazida até os dias atuais e interfere diretamente na capacidade de atuação das mulheres que desejam adentrar no rol político, ou até mesmo as pautas trazidas por mulheres devem conter um certo tipo de demanda, sempre abarcando o cuidado e a reprodução feminina, dois atributos ligados exclusivamente ao gênero.

Diante dos números do TSE se percebe que mesmo após a criação da Lei de Cotas a participação feminina na esfera pública é rodeada por uma série de elementos que fazem com que as mulheres ainda sejam parcela irrisória na política. Nessa mesma linha de pensamento, a divisão sexual do trabalho também é outra forma eficaz, antiga e excludente utilizada para exilar as mulheres do cenário público. Essa divisão corrobora a dicotomia público/privado a qual a mulher ainda está inserida, mesmo tendo o movimento feminista quebrado barreiras significativas (PINHEIRO, 2006). A exemplo disso, na maioria das casas brasileiras, as tarefas domésticas raramente são compartilhadas, ficando sob exclusiva responsabilidade das mulheres. Segundo o Ipea (2016, p. 37),

Nos domicílios, conforme aumenta o número de filhos, menor é a proporção de homens que cuidam dos afazeres domésticos. Nas famílias com nenhum filho, $54,6 \%$ dos homens e $94 \%$ das mulheres se dedicam a estas atividades. Nos domicílios com cinco filhos ou mais, são apenas 38,8\% dos homens, para $95,7 \%$ das mulheres cuidando destes afazeres. [...]. Apenas a posse de máquina de lavar impacta o número de horas despendidas nesta atividade: as mulheres que a possuem dedicam 25,4 horas semanais, passando para 28,2 horas quando não têm acesso a este bem, e os homens, de 10,1 para 11,6 horas.

Esse cenário devastador demonstra que a mulher que almeja buscar uma candidatura, além de manter um trabalho remunerado, precisar laborar em casa, sendo a principal responsável pelas tarefas domésticas de cuidado. Somando-se a isso, essa mulher ainda precisa se adequar a agenda partidária, cuja participação no partido é majoritariamente composta por homens que não precisam enfrentar essa realidade. Neste sentido, a mulher necessita participar dos espaços políticos, mas para que se seja eleita, deve preencher um estereotipo de mulher "mãe, esposa, bonita bem vestida, que saiba se comportar" (VERDADE, 2013, p. 107). O ideário de mulher perfeita perfaz o perfil das candidatas que conseguirão se eleger, isso porque as mulheres que fogem de padrões sociais são consideradas radicais, inconstantes, e inconfiáveis, e desse modo inadequadas ao espaço patriarcal da política. 
Um breve comentário que merece ser destacado é que o perfil de muitas mulheres eleitas nas eleições de 2018 é um perfil de militância feminista. As novas mulheres eleitas estão saindo do estereótipo de mulher do lar e boa mãe e estão assumindo um papel menos conservador e mais radical que engloba agora a definição de feminista, característica essa anteriormente desprezada tanto pelas mulheres como pelos partidos. Esse elemento não terá maior explicitação na pesquisa tendo em vista o tamanho do estudo e que o objetivo não é traçar perfis, mas pode ser um indicativo de que a política feminina está se modificando.

Outro fator de relevância nessa mesma temática é que, Para Miguel e Biroli (2011), por muito tempo a mídia contribuiu negativamente na construção da imagem feminina, fazendo com que pareça estranho ter mulheres na política quando essas não atuam no rol doméstico, sendo boas mães, esposas ou filhas. Contudo, a contrariedade reside no fato de que a atuação no privado, por si só retira, ou ao menos diminui em grande monta a possibilidade de as mulheres alcançarem altos cargos de poder dentro do público.

As reportagens apresentam a confirmação do "pertencimento" da mulher à vida privada ao colocar a condição de mulher solteira como um estigma e uma razão para a atuação política. Por outro lado, a vida política pode, ao mesmo tempo, constituir a exceção que justifica a ausência na vida doméstica e que pode levar ao fim do casamento. É o caso de Emília Fernandes, que foi senadora e posteriormente, ministra da Secretaria Especial de Políticas para as Mulheres. Em seu perfil, ao ser eleita senadora pelo PTB do Rio Grande do Sul aos 45 anos, estão as informações de que "não cozinha", "não faz as compras do supermercado" e "não cuida da casa". (Época, 19 out. 1994, p.42). Seis anos depois uma reportagem da mesma revista sobre a conquista de posições de destaque e de poder por mulheres brasileiras fala da presença de Fernandes na Mesa Diretora do Senado. Entre referências às maquiagens e roupas, menciona que a Senadora "é tão devotada ao mandato que viu ruir o casamento de 31 anos" (MIGUEL; BIROLI, 2011, p.173-174).

Portanto, a imagem das mulheres políticas, bem como seu status dentro do privado, ainda são aspectos basilares para avaliar sua conduta na área pública. O sucesso na política poderia implicar o fracasso na vida familiar. Obviamente, cabe destacar que o mesmo não ocorre no que tange aos homens, para os quais a atuação no âmbito doméstico pouco ou nada interfere na sua avaliação política. E esta lógica é utilizada, muitas vezes, pelos próprios partidos políticos que, em sua estruturação patriarcal interna auxiliam de forma diferenciada seus candidatos, em virtude da sua "importância", "liderança” ou capital político. 
José Alves (2010, p. 24), referindo-se sobre a pouca participação feminina, relata que tal ocorrência não é pela falta de mulheres aptas para concorrer nas eleições, mas tudo depende "do modo que os partidos são organizados: 'Eles são controlados por homens, que dão pouco espaço para as mulheres estruturarem suas campanhas"”. Nesse ínterim, os próprios partidos favorecem o masculino, proporcionando maior visibilidade e empreendimentos econômicos que facilitam a campanha. Desse modo, ressalta-se que "os partidos selecionam os candidatos, comandam as campanhas, seus tópicos e questões programáticas, organizam os representantes em bancadas" para que ocorra o processo representativo (VERDADE, 2013, p. 89). Diante dessas asserções, conclui-se que os partidos são estruturas com objetivos bem definidos e, muitas vezes, esses objetivos não enfocam a mulher.

Esta priorização partidária às campanhas masculinas tem como fator relevante de atuação a questão econômica. Conforme Clara Araújo (1999) já afirmava, fatores econômicos são os aspectos basilares para que as mulheres não sejam direcionadas para o público. De acordo com Verdade (2013), os investimentos do TSE, conforme a transparência dos dados eleitorais, apontam que os recursos utilizados nas campanhas eleitorais refletem que os indivíduos que arrecadam mais recursos econômicos são eleitos com mais facilidade, os dados também demonstram que as mulheres arrecadam infinitamente menos recursos que os homens. As tarefas primordiais de uma campanha, como montar um comitê, se comunicar com o eleitor, apresentar propostas, divulgação de ideias, demandam dinheiro, e se o candidato não dispuser desses recursos, com certeza não será eleito.

Além da questão financeira, Araújo (1999) destaca a existência de uma espécie de processo seletivo definidor de quem poderá ou não promover uma candidatura. Neste processo, a própria burocracia que integra o pedido de candidatura desestimula muitas mulheres, especialmente em cidades pequenas do interior: o período pré-candidatura requer registro e oficialização de um candidato, para isso, precisa-se de assistência jurídica para lidar com os trâmites legais e burocráticos. Como resultado dessa burocratização, os índices de reprovação de registros de pré-candidatos são mais altos entre as mulheres do que os candidatos homens.

Em que pese a Lei de Cotas ser uma facilitadora da entrada feminina no rol público, a política em si oferece mecanismos de controle de "quais" mulheres estarão aptas a participar 
do jogo de poder e quais estarão banidas deste jogo. Mulheres que se proponham a defender pautas progressistas, tais como a igualdade de gênero e a paridade de participação e de direitos entre homens e mulheres, e que tenham como pressuposto a alteração da lógica de poder e do status quo, por vezes acabam barradas do espaço político e dificilmente conseguem espaço e capital político suficientes para serem eleitas.

O capital político, neste sentido, constitui outro elemento fundamental para a exclusão das mulheres de vitórias em processos eleitorais. O capital político, segundo Miguel (2014), é um mecanismo pelo qual se identifica uma pessoa que participa da área política, atuando, propondo mudanças, representado indivíduos, explanando discursos, enfim, modificando a sociedade para um grupo de pessoas que é representado por alguém que já integra o espaço público. Partindo da premissa de que as mulheres foram consideradas inferiores e submissas durante séculos, o capital político é realmente um atributo que não é avistado na mulher. Considerando que o capital como um acúmulo de vivências políticas, se a mulher não possui atuação dentro desta área, com certeza será difícil que ela seja eleita, ou que consiga se destacar no partido que engloba.

Neste sentido, Miguel (2014) ratifica a posição aqui defendida, de que a desigualdade de gênero atinge o capital político de tal forma que retira das mulheres a possibilidade de atuação no público. Isto porque, no rol público, as mulheres também precisam adquirir influências para movimentar o “jogo". A obtenção de capital político e relações mútuas de apoio requerem sua introdução em atividade de evidência no partido. Para tanto, existem temas a serem defendidos e debatidos, e os temas representativos para mulheres não acumulam capital político, tampouco às levam a serem aprovadas por todos.

A par disso, muitas mulheres em busca de capital político escolhem como bandeiras eleitorais temas menos polêmicos e mais aceitos pela lógica patriarcal. Mais do que isso, mulheres que adentram na política, para serem eleitas e terem sucesso, acabam muitas vezes se adaptando à estrutura patriarcal da política, e não modificando-a, tal como se esperava inicialmente. Tais mulheres apenas reproduzem o modo de fazer política masculino e autorizado pelo patriarcado, não apresentando uma capacidade de atuação que possa repercutir significativamente na qualidade de vida e empoderamento das demais mulheres de sua comunidade. 
Deste modo, torna-se possível compreender o aparente paradoxo anteriormente citado: o suposto empoderamento de mulheres, inclusive na vida política, a ponto de serem eleitas, e a aparente desvalorização da necessidade de políticas públicas de igualdade de gênero e de empoderamento de outras mulheres enquanto grupo. Muitas vezes, mulheres, mesmo que adentrem em espaços privilegiados de poder político, não compreendem ou não enxerguem prioridade na implantação e efetivação de políticas públicas para mulheres, pois sua atuação apenas reproduz a ordem vigente, e somente enquanto tal, seu espaço na política é construído e viabilizado e autorizado.

\section{CONSIDERAÇÕES FINAIS}

Diante do que a pesquisa intentou demonstrar, conclui-se a investigação acreditando que a desigualdade de gênero encontrada no período contemporâneo, de um modo geral, faz com que as mulheres reivindiquem cada vez mais por paridade, tendo a necessidade de comprovar sua capacidade diante do mundo público, para que então seja possível alcançar locais já conquistados pelos homens. Em análise à Lei de Cotas, conclui-se que de acordo com os números expostos ela apresenta índices positivos. Embora possam parecer inexpressivos, de algum modo os números vêm aumentando, respondendo o problema de pesquisa de que a Lei proporcionou uma maior participação política as mulheres. A representatividade feminina é, com certeza, o elemento chave da mulher na política. Sendo a sociedade brasileira um composto de sujeitos plurais, muitos que já se encontram em situação de poder atuam de modo a favorecer seu grupo de reconhecimento, o dever da mulher na política, acredita-se, é proporcionar a representatividade das que mais precisam de atenção.

A pesquisa realizada demonstra que não basta adentrar na política, mais do que participar desse núcleo, é imperioso deter representatividade na participação buscando demandas femininas. Embora os números venham crescendo, muitos são os argumentos que justificam as dificuldades encontradas pelas mulheres para se inserir e permanecer na área pública. Inicialmente, a crença na inferioridade feminina é uma das razões que desestimula a entrada delas em um âmbito preponderantemente masculino. A divisão sexual do trabalho, a qual designa a dupla jornada feminina retira da mulher as forças necessárias para aprimorar suas habilidades políticas, bem como crescer dentro desse espaço. A carência de tempo livre 
faz com que elas detenham menor capital político e consequentemente sejam menos votadas, ainda, elas possuem menor espaço na propaganda política e recebem menor atenção dos partidos que compõem.

A partir de tudo que foi demonstrado nessa pesquisa, lamentavelmente, os resultados apontam que as mulheres ainda não atuam livremente no âmbito público e precisam de muito esforço para modificar a situação social através do político. A representatividade ainda é carente, mulheres eleitas, em sua maioria, não atuam para outras mulheres, resultando em uma total falta de amparo e descaso, corroborando que ainda é necessário que ocorra a conquista de prerrogativas que possibilitem mais paridade. A desigualdade de gênero ainda permeia a sociedade, desse modo, é preciso desconstruir a cultura patriarcal trazida até a atualidade para que seja possível viver/atuar em uma sociedade menos desigual e que aufira aos sujeitos direitos políticos e sociais paritários.

Sendo assim, a reprodução do modo masculino de fazer política acaba sendo evidência, mesmo quando envolve a participação política das mulheres, de modo que, nem sempre a eleição de mulheres repercute diretamente nas necessidades femininas. Como já afirmava Simone de Beauvoir, em 1980, "não se nasce mulher, torna-se". Adaptado ao estudo aqui realizado, poderíamos afirmar, 30 anos depois, que ainda hoje não basta ser mulher na política para poder representar as mulheres. Mais do que simplesmente mulheres, a política necessita de mulheres dispostas a alterar o modo tradicional e patriarcal de fazer política, e cuja atuação possa repercutir positivamente na promoção da paridade participativa e de direitos para todas as mulheres de sua sociedade.

\section{REFERÊNCIAS}

ALVES, José (Org.); PINTO, C. R. J. (Org.) e JORDÃO, F. (Org.). Mulheres nas eleições 2010. Rio de Janeiro: ABCP/Secretaria de Políticas para as Mulheres, 2012.

ALVES, Branca Moreira; PITANGUY, Jacqueline. O que é feminismo? São Paulo: Brasiliense, 2003.

ARAÚJO, Clara M. Cidadania incompleta: o impacto da lei de cotas sobre a representação política das mulheres no Brasil. Tese em Sociologia e Antropologia. Rio de Janeiro: UFRJ. 1999.

BANDEIRA, Lourdes Maria. Violência de gênero: a construção de um campo teórico e de investigação. Revista Sociedade e Estado, vol. 29, núm. 2, maio-agosto, 2014, pp. 449-469 Universidade de Brasília: Brasília. 
BEAUVOIR, S. de. O segundo sexo. Rio de Janeiro: Nova Fronteira, 1980.

BESTER, Gisela. Aspectos históricos da luta sufrágica feminina no brasil. Revista de Ciências Humanas, Florianópolis, v. 15, n. 21, p. 11-22, 1997.

BIROLI, Flávia. Mulheres e política nas notícias: estereótipos de gênero e competência política. Revista Crítica De Ciências Sociais, 2010. Ed. 90, p. 45-69, 2010.

BOURDIEU, Pierre. Observações sobre a história das mulheres. In: As Mulheres e a História. Lisboa: Dom Quixote, 1995.

COELHO, Rebeca. Contextos de participação política de mulheres: as candidaturas das prefeitas Maria Luiza Fontenele (1985) e Luizianne Lins (2004). Recife. 2014.

COLLING, Ana Maria. A construção da cidadania da mulher brasileira. Igualdade e Diferença. Ijuí: UNIJUI, 2000.

INSTITUTO DE PESQUISA ECONÔMICA APLICADA - IPEA et al. Retrato das desigualdades de gênero e raça. Brasília: Ipea, 2011. $4^{\mathrm{a}} \mathrm{ed}$.

LAKATOS, Eva; MARCONI, Marina. Fundamentos de metodologia científica. Editora Atlas, São Paulo, 2003

MARQUES, Danuza. O que são cotas para mulheres na política e qual é sua importância? Blog Gênero e Número. 2018. Disponível em:

http://www.generonumero.media/o-que-sao-as-cotas-para-mulheres-na-politica-e-qual-e-suaimportancia/ Acesso em: 10 de agosto de 2018.

MENUCI, Júlia. A efetividade da participação política de mulheres quanto à questões de gênero: mulheres eleitas promovem políticas públicas para mulheres? Porto Alegre: Editora Fi, 2018. Disponível em: https://www.editorafi.org/product-page/571-julia-menuci\#!

MIGUEL, Luís Felipe; BIROLI, Flávia. Caleidoscópio convexo: Mulheres, Política E Mídia. São Paulo: Editora Unesp, 2011. $1^{\text {a }}$ ed.

MIGUEL, Luís Felipe; BIROLI, Flávia. Feminismo e política. São Paulo: Boitempo, 2014.

NIELSSON, Joice Graciele. O liberalismo democrático-igualitário e a justiça feminista: Um Novo Caminho. Tese de doutorado apresentado ao Programa de Pós-graduação em Direito da Universidade do Val do Rio dos Sinos - UNISINOS, 2016. Disponível em: http://www.repositorio.jesuita.org.br/bitstream/handle/UNISINOS/6094/Joice+Graciele+Niels son_.pdf;jsessionid=A5C1EF7520597A5192CEBDA65EE2D25E? sequence $=1$ Acesso em 5 de abril de 2017. 
PARADA, Eugenio Lahera. Política y políticas públicas. In: SARAIVA, Enrique. FERRAREZI, Elisabete. Políticas públicas; coletânea. Brasília: ENAP, 2016. 3 v.

PATEMAN, Carole. O contrato sexual. Tradução Marta Avancini. Rio de Janeiro: Editora Paz e Terra, 1993.

PERROT, Michelle. Minha história das mulheres. São Paulo: Editora Contexto, 2007

PINHEIRO, Luana. S. Vozes femininas na política: Uma análise sobre mulheres

Parlamentares no pós-Constituinte. Brasília: Secretaria Especial de Políticas para as Mulheres, 2006.

PINTO, Celi. Dossiê. Feminismo história e poder. Curitiba: Revista de Sociologia e Política, 2010.

PULEO, Alicia, Filosofía, género y pensamiento crítico. Valladolid: Universidade de Valladolid, 1999.

SAFFIOTI. Heleieth. Gênero, patriarcado e violência. São Paulo. Editora Fundação Perseu Abramo, 2004

SCOTT, J. W. Gênero: uma categoria útil de análise histórica. Porto Alegre: Educação e Realidade, 2005.

TRIBUNAL SUPERIOR ELEITORAL - TSE. Número de mulheres eleitas em 2018 cresce em 52,6\% em relação a 2014. Brasília: 2018. Disponível em:

http://www.tse.jus.br/imprensa/noticias-tse/2019/Marco/numero-de-mulheres-eleitas-em2018-cresce-52-6-em-relacao-a-2014 Acesso em: 05 de agosto de 2019.

VERDADE, Kelly. As mulheres e a democracia representativa no Brasil. Uma análise do Sistema Eleitoral Brasileiro. Rio de Janeiro, 2013. 